\title{
Dolly researcher plans further experiments after challenges
}

[PARIS] Ian Wilmut, the Scottish researcher whose group last year reported the cloning of Dolly the lamb from the udder cell of an adult ewe, is planning further experiments to clarify the lamb's origin — and has offered to make frozen tissue from the donor ewe available to other researchers.

The move comes as many embryologists around the world have rallied to Wilmut's defence in rejecting challenges to Dolly's authenticity and playing down the significance of criticisms that his paper (Nature 385,$810 ; 1997$ ) lacked unequivocal evidence that Dolly was derived from an adult cell.

The controversy has been triggered by a letter in Science describing Dolly as an "anecdote not a result", referring to the fact that it was the only successful birth out of several hundred attempts. The letter was written by Norton Zinder, a bacterial geneticist at Rockefeller University in New York, and Vittorio Sgaramella, a scientist at the University of Calabria in Italy (Science 279, 635; 1998).

The two researchers criticize what they claim was the poor characterization of the donor cells. They restate the possibility that Dolly could have originated from a stem cell

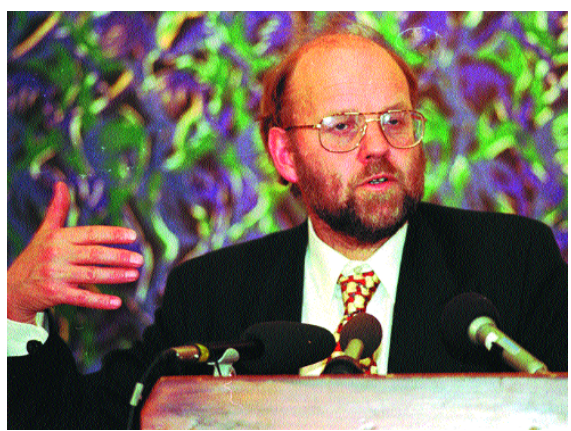

Wilmut: "small possibility" that cloning was the result of inadvertently using a fetal cell.

— as noted in Wilmut's paper — and perhaps even from a circulating fetal cell, as the donor ewe was pregnant at the time the cells were obtained. They argue that the lamb's origins would have been better clarified by a genetic fingerprinting comparison with the donor ewe.

In fact, cells used in the cloning experiments were taken from a ewe that died three years before Dolly was born, and Wilmut's team did not directly compare Dolly's DNA with that of her clone. Ron James, managing director of PPL Therapeutics, which spon-

\section{French agency faces fresh controversy}

[PARIS] An inquiry by France's ministry of national education, research and technology into the activities of a laboratory of INSERM, the national biomedical research agency (see Nature 391, 519; 1998), is likely to take a new turn following a request from two scientists that their names be removed from a key paper based on work at the laboratory that is being considered for publication.

In the letter dated 17 February to the US journal Proceedings of the National Academy of Sciences (PNAS), the scientists from the INSERM Laboratory of Nutrition, Lipoprotein Metabolism and Atherosclerosis at the University of Rennes 1 ask that their names be removed from a paper entitled "Leptin acutely regulates postprandial lipemic responses in ob/ob and $\mathrm{db} / \mathrm{db}$ mice" and from any revised versions.

"The main point is that we disagree with the use and misinterpretation of our data by Mr B. Bihain [the director of the laboratory]," wrote the two researchers. "Moreover, despite the fact that we are ... authors, we did not take part in the [editing] of the paper and we did not sign any document for this submission."

In an even blunter letter sent in January to Jacqueline Godet, director of life sciences at the ministry and a participant in the inquiry, the authors say that they are unable to accept being co-authors of "incorrect" results. "Now that these falsified data may appear in an international publication, casting doubts on our scientific integrity, we have taken the liberty of asking you what we should do," they write, enclosing a series of annexes detailing the conduct of research within the laboratory.

Nick Cozzarelli, the chief editor of PNAS, says the paper is at the first stage of its review process, which is conducted by a member of the academy, in this case Richard Havel from the School of Medicine at the University of California, San Francisco. The paper has so far received favourable reviews from referees, although it has not yet been submitted to the editorial board.

"Of course, we would never leave on a paper the names of individuals who wish to have them removed," says Cozzarelli. He adds that, without wishing to prejudge a paper that has not yet been received by the editorial board, "given the history of the case, it is highly likely that the board would re-evaluate the suitability of the paper if it gets to us".

Declan Butler \& Olivier de Gandt sored Wilmut's work, admits that in retrospect it would have been prudent to have taken more precautions.

But he explains that the mammary gland cells used had not been better characterized because they were prepared for other studies aimed at increasing expression of milk proteins, and had not been created with nuclear transfer experiments in mind.

This explanation cuts little ice with critics such as Richard Gardner, an embryologist at the University of Oxford. "I don't believe this was an 'after-tea' experiment," he says. "It should have been better documented." Gardner describes the absence of a direct comparison between Dolly and her clone as a "staggering omission", leaving open the possibility of a mix-up in the cells used. Others who have criticized the relative lack of evidence include the Nobel laureate Walter Gilbert of Harvard University.

Wilmut has argued that a mix-up of cell cultures was unlikely, given that Dolly is a Finn Dorset ewe, and that no other Finn Dorset cells were being cultured in the laboratory. But he admitted last week that, although the prospect is highly unlikely, there is a small possibility that Dolly could have originated from a fetal cell, and that he may repeat the experiments.

In response to the criticisms, PPL has asked an unnamed US university to verify that Dolly's mitochondrial DNA came from the Scottish Blackface breed of sheep used as a source of unfertilized eggs, and an unnamed British team to compare Dolly's DNA with that of stored samples of the udder cells.

A definitive answer should come from a comparison of Dolly's DNA with tissues from the donor ewe. Wilmut says frozen samples were kept, and are being studied by an independent group. "Other samples will also be available to interested parties if they wish," he says.

Many cloning scientists have come to Wilmut's defence. James Robl, a scientist at Texas Transgenic Nuclear Transfer Calves, describes Zinder and Sgaramella's criticisms as "nitpicking". He says they are "out of touch" with cloning research. Robl argues that, far from being an "anecdote", one birth from 277 attempts is a "very respectable result in this field where there are many steps, each of which take their toll on efficiency".

Robl dismisses as highly imp robable the possibility that Dolly might have originated from a fetal cell, given that the sheep placenta contains many layers of tissues separating the fetus from the mother's blood.

Ken White, a cloning scientist at Utah 
State University, says: "Retrospectively you can say that we can't go back and check, but it is always easy to look back. I don't think that Ian Wilmut needed to do more." He adds: "I wouldn't be so quick to run up red flags saying that no-one has been able to reproduce the work. It's too soon. If by 2000 no-one has duplicated it, I'll start being concerned. But am I concerned in 1998 ? Not at all."

Zinder and Sgaramella argued that their scepticism had been provoked by the fact that no-one has reproduced the results. But David Wells, a scientist at the Ruakara agriculture research centre in New Zealand, who has reproduced Wilmut's work on cloning from fetal fibroblasts, and is engaged in cloning adult bovine cells, describes the controversy as "premature".

Wells says it is unfair to expect rapid confirmation of the results, given the time and money needed for such experiments, the long gestation periods of farm animals and the seasonality of their reproduction.

Bob Moore, who has recently retired as deputy director of the Babraham Agricultural Institute near Cambridge, says he is not surprised that other scientists have not yet repeated Wilmut's finding, given the difficulties of obtaining success. "I think people are having difficulties reproducing the results, but you only have to look at [the low efficiency of] Wilmut results to predict that they should be having difficulties."

Moore describes the controversy as a "storm in a teacup". He points out that Dolly is part of a growing body of science that has witnessed a logical progression from the production of clones from embryos, and differentiated fetal fibroblasts, to the routine generation of embryos from adult somatic cells, even though, apart from Dolly, none have gone to term.

Jean-Paul Renard, a scientist at the French national agricultural ag ency INRA, who is attempting to clone cattle from adult cells, is even more confident. "Our work leads us to think that Dolly is a reality, and will be reproduced," he says.
James argues that, contrary to popular belief, few groups are racing to reproduce the Dolly experiment. For commercial purposes, cloning from fetal fibroblasts is more efficient, while their genetic modification is relatively straightforward, he says. "It delivers what we need - a genetically modified animal." Wilmut's group has so far not attempted to repeat the experiment simply because "Dolly is not commercially useful," James argues.

"You are talking at least \$1 million" to repeat the Dolly experiment, says Robl. He is also pursuing cloning from fetal fibroblasts as the most immediately promising commercial option, while car rying out research to develop more efficient systems for cloning from adult cells.

Zinder remains unconvinced by such arguments, asserting that the extensive media and political reaction to cloning has obscured the fact that "the emp eror has no clothes". He says Wilmut should have been required to repeat the result before his paper was published.

Declan Butler

\section{Genome panel defends researchers' - and families' - interests}

[WASHINGTON] The latest recommendations from the international organization that coordinates the work of genome researchers are meeting criticism from those seeking to defend patients' privacy. The organization wants scientists to retain the ability to gather more information about DNA samples from subjects' medical records, and researchers to be able to overrule subjects in some cases by informing family members about their findings.

The ethics committee of the Human Genome Organisation (HUGO) also recommends that research samples obtained with consent and stored "may be used for other research" if subjects are informed at the time of the original donation and do not object - and provided that information identifying the subject is either replaced with a code allowing the individual to be traced, or stripped from the samples.

But HUGO's statement expresses strong reservations about the irreversible 'stripping' of information. Even if it is appropriate in certain circumstances, it should be done with caution, "since it may preclude valuable uses of the samples and validation of results".

The retention of codes allowing subjects to be traced would mean that a subject might be contacted years after participating in a research trial by researchers pursuing another study. Some privacy advocates argue that this should happen only in rare, extenuating circumstances. Virtually all oppose it as a general policy.

Many scientists feel strongly that irreversible loss of access to subject information seriously damages a sample's value. For instance, stored tumour samples might be found to contain a particular oncogene, but its prognostic value would be impossible to discover if subjects or their records could not be traced.

Bartha Maria Knoppers, a law professor at the University of Montreal and chair of the HUGO ethics committee, says the statement seeks to define an ethical middle ground between allowing researchers unfettered access to samples and attached clinical information, and requiring specific informed consent for each use of a sample.

The statement was drafted by scientists, ethicists and lawyers from ten countries. Its publication comes as governments, international organizations and societies around the world are working to define ethical standards for the use of DNA samples that neither hobble research nor trample on patients' rights.

In the United States, researchers can at present gain access to tissue samples gathered for other research, or through clinical practice, by persuading local ethics boards that they are essential to a study, and that their use will not harm subjects.

The ethics committee studied some 75 statements by private, national and international groups before coming to its conclusions. It will present them to HUGO members at a meeting in Turin, Italy, late next month. The HUGO statement is not legally binding but "is meant to inspire national approaches", says Knoppers.

HUGO's caution about irreversibly stripping identifying information from samples, and its recommendation that researchers should be able to use samples collected for one purpose for other studies, is welcomed by Mark Sobel, chief of the molecular pathology section at the US National Cancer Institute and president-elect of the Association for Molecular Pathology. The recommendations are "wonderful," he says. "They would be consistent with what most research communities and the pathology community would want."

But others say the statement bends too far towards researchers' interests. Retaining links to enable a researcher to obtain more information raises "real concerns about the invasion of privacy" that have not been given "adequate acknowledgement or weight" by the HUGO committee, says Ellen Wright Clayton, associate professor of paediatrics and law at Vanderbilt University in Nashville, Tennessee.

Clayton was lead author of a more conservative 1995 statement by a working group convened by the US National Institutes of Health and the Centers for Disease Control and Prevention.

The HUGO statement also recommends that researchers should be allowed to overrule a subject's wishes that blood relatives should not be informed of findings, if the findings point to "a high risk of having or transmitting a serious disorder and prevention or treatment is available".

"Genetic information is both personal and familial," says Knoppers. "We can't just [exclude] the real and morally valid interests of family members.” But not all researchers agree. "I have trouble with overriding an individual's need for privacy except in an immediately life-threatening situation," says Sobel. Meredith Wadman 